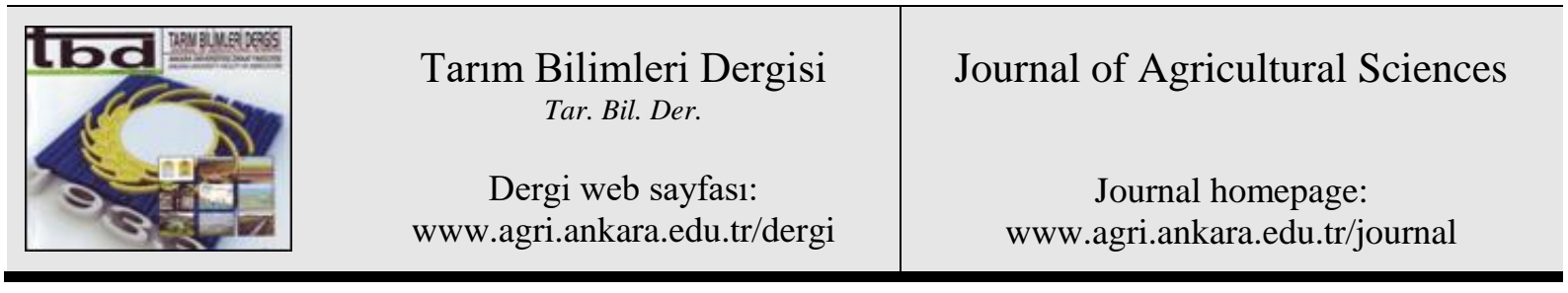

\title{
Eggshell Water Vapor Conductance and Shell Structural Characteristics of Broiler Breeder in Different Flock Ages
}

\author{
Ümran ŞAHAN"a, Saliha SABAH ${ }^{\mathrm{a}}$, Arda SÖZC ̈̈ ${ }^{\mathrm{b}}$

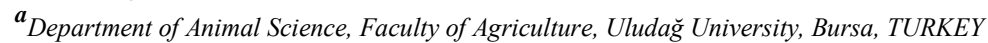 \\ $\boldsymbol{b}$ Ödemiş Vocational High School, Dairy and Livestock Programme, Ege University, İmir, TURKEY
}

\section{ARTICLE INFO}

Research Article

Corresponding Author: Ümran SAHAN, E-mail: umran@uludag.edu.tr, Tel: +90 (224) 2941553

Received: 16 October 2018, Received in Revised Form: 14 December 2018, Accepted: 25 March 2019

\section{AUTHORS ORCID ID}

(Ümran ŞAHAN: 0000-0002-4912-0551), (Saliha SABAH: 0000-0003-4577-8054), (Arda SÖZCÜ: 0000-0002-0955-4371)

\begin{abstract}
The aim of the study was to investigate eggshell traits; including eggshell water vapor conductance, eggshell thickness, pore density, egg weight loss as well as eggshell surface area and volume in 28 and 40 week-old broiler breeders. Furthermore, the phenotypic correlations among the eggshell characteristics were determined. The eggs were ranged from $54.41 \mathrm{~g}$ to $60.78 \mathrm{~g}$ and $54.71 \mathrm{~g}$ to $60.62 \mathrm{~g}$ in 28 and 40 wk-old age groups, respectively. All eggs were weighed and numbered before setting and were monitored individually until the end of the incubation. Mean eggshell water vapor conductance $(G)$ value
\end{abstract}

was $11.00 \pm 1.01 \mathrm{mg} \mathrm{H}_{2} \mathrm{O}$ day $^{-1}$ torr $^{-1}$ in 28 wk-old flock and $11.99 \pm 1.28 \mathrm{mg} \mathrm{H}_{2} \mathrm{O}$ day $^{-1}$ torr $^{-1}$ in 40 wk-old flock respectively $(\mathrm{P}<0.05)$. The mean value of shell thickness and pore density mean along with the two regions (broad end and equator) were higher and significant in 28 wk-old flock $(\mathrm{P}<0.01)$. Egg weight loss was not found to be significant. Surface area was higher in 40 wk-old flock while as volume was higher in 28 wk-old flocks $(\mathrm{P}<0.01)$. There was no correlation between eggshell thickness and pore density. Both eggshell thickness and pore density were having significant positive correlation along with three eggshell regions in each flock ages $(\mathrm{P}<0.01)$.

Keywords: Water vapor conductance; Eggshell thickness; Pore density; Correlation

\section{Introduction}

Water vapor conductance is one of the important factors that influence the embryonic gas exchange and development of the embryo (Hamidu et al 2007). Moreover, it determines the respiratory pattern of the egg that is influenced by eggshell properties including the number of pores and thickness of eggshell (Peebles \& Brake 1987). During embryonic growth, the gas exchange of the avian embryo is limited by the diffusion of gases through the pores of the eggshell. However, few studies have carried out on the influence of genetic selection of eggshell characteristics, like eggshell conductance (Tullett 1990). It has been observed that eggs from older hens have higher eggshell water vapor conductance, this variation could have arisen from the difference of the breeder age (Roque \& Soares 1994). Therefore, to make an ideal gas exchange during the embryonic development, the conductance of eggshell should be considered as a functional tool besides other factors like a gaseous composition, barometric pressure of the surrounding natural air, the hatchery ventilation rate, humidity and embryonic oxygen uptake (Visschedijk 1991).

Changes in shell porosity have been seen among flocks of different ages. Tullett (1981) found these changes are because of the number and cross-sectional area of the pores and not due to the thickness of the eggshell. Ipek 
\& Sahan (2001) found that eggs were obtained from different broiler flock ages with different egg weight influences the eggshell quality. Additionally affects the egg weight loss, hatchability performance and chick quality (Bamelis et al 2008). Roque \& Soares (1994) reported that eggshell water vapor conductance $\left(\mathrm{GH}_{2} \mathrm{O}\right)$ also affects hatchability in broiler hatching eggs. Peebles et al (2000) reported that when the flock age increase, weight of egg and yolk sac percentage of embryo increase, whereas the thickness of shell decreases. Vieira \& Moran (1999) have also reported that yolk sac percentage of embryos from smaller eggs was greater when compared to larger eggs of similar ages.

The aim of the study was to investigate eggshell traits; including eggshell water vapor conductance, eggshell thickness, pore density, egg weight loss as well as surface area and volume in two broiler breeder ages. Furthermore, the phenotypic correlations among the eggshell characteristics were determined.

\section{Material and Methods}

\subsection{Experimental design and parameters}

The care and use of animals were in accordance with the laws and regulations of Turkey and approved by the ethics committee of Uludag University (License Number 2018-05/01). A total of 130 hatching eggs were obtained from commercial Ross 308 broiler breeder flock at 28 wk and 40 wk-old age on the same day. The flocks were reared and kept under standard management conditions according to breeder company recommendation (Aviagen 2010). A standard breeder diet was given to both of the flocks (16.0\% CP and 2750 $\mathrm{kcal}$ of $\mathrm{ME} \mathrm{kg} \mathrm{ge}^{-1}$ ) between 22 and $65 \mathrm{wk}$ of age. The nutrient content of the diet was prepared according to the NRC (1994) specifications. Eggs were stored at $18{ }^{\circ} \mathrm{C}$ and $65 \%$ relative humidity for 3 days then pre-warmed for 8 hours at room temperature of $22^{\circ} \mathrm{C}$. Eighty eggs were incubated to investigate eggshell traits and chick quality parameters. The eggs were ranged from $54.41 \mathrm{~g}$ to $60.78 \mathrm{~g}$ in 28 wk-old flock age group and from $54.71 \mathrm{~g}$ to $60.62 \mathrm{~g}$ in 40 wk-old flock age group. The eggs were numbered and weighed with $\pm 0.01 \mathrm{~g}$ precision and were monitored one by one during the incubation period. Eggs were incubated at $37.5^{\circ} \mathrm{C}$ and $55 \% \mathrm{RH}$ in an incubator (setter T640 Cimuka Inc) during 18 days of incubation. On the $18^{\text {th }}$ day of incubation, eggs were weighed to determine egg weight loss and were transferred to the hatcher (Hatcher; Cimuka Inc., Ankara, Turkey). Eggs were kept in separate chambers within trays at $37.0^{\circ} \mathrm{C}$ and $60 \% \mathrm{RH}$.

\subsection{Eggshell thickness}

On the $22^{\text {nd }}$ day of the incubation period, the hatched chicks were removed from the hatcher and only the eggshells of hatched eggs were individually stored in the plastic bags for the determination of eggshell thickness and large pore count. Unhatched eggs were opened for visual assessment of fertility and embryonic mortalities. Embryonic mortality was separated into three groups: early term (1 to 7 day of incubation), mid-term (8 to 14 day of incubation), and late-term (15 to 21 day of incubation).

Eggshells from hatched chicks were collected, washed and dried for 24 hours at room temperature. The thickness of eggshell was measured from three different regions of eggs (broad end, equator and narrow end) with the help of ball-point caliper having reading $0.01 \mathrm{~mm}$ (Peeble \& Cristropher 2013). The thickness of eggshell measurements was conducted by excluded the membranes that were adhered to the eggshell.

\subsection{Pore density}

Same eggshell regions were also used to measure large pore count. These eggshell regions were dipped in 5\% $\mathrm{NaOH}$ solutions $\left(\mathrm{gr} \mathrm{liter}^{-1}\right.$ ) for 5 to 10 minutes to remove all shell membrane or other adhered material. Furthermore, for the magnification of pores eggshell regions were dipped in concentrated nitric acid for about 15 seconds. By using aqueous Methylene Blue dye $(0.5 \mathrm{~g}, 89 \%$ dye in $1 \mathrm{~L}$ of $70 \%$ ethanol) the surface of the eggshells were tinted following drying (Board \& Halls 1973). In this study, for the determination of pore density, only the large pores were counted under the microscope. The counting field was $0.50 \mathrm{~cm}^{2}$, and representing three regions (broad end, equator and narrow end) of each egg. For the measurement of average values, estimated values were multiplied by 2 that expressed the pore density per centimeter. Calculation of total surface area formula, A $\left(\mathrm{cm}^{2}\right)=4.835 \mathrm{~W}^{0.662}$, where $\mathrm{W}=$ initial egg mass $(\mathrm{g})$. Likewise estimated values of area and shell 
thickness were used to calculated the volume of the derived egg by multiplying area and shell thickness (volume is equal to A multiplied by L, where A refers to surface area of the eggs in centimeter square and L refers to thickness of shell in centimeters) (Paganelli et al 1974).

\subsection{Conductance}

A total of 50 freshly laid eggs from each flock were individually weighed, numbered and there initial weight was recorded to determine only the eggshell water vapor conductance $\left(\mathrm{GH}_{2} \mathrm{O}\right)$. At $25{ }^{\circ} \mathrm{C}$ the eggs were set in desiccators along with the silica gel to make sure there is zero humidity (Visschedijk 1983). Consecutively for four days, eggs were weighed one by one to measure the rate of weight loss. Water vapor shell conductance was determined in terms of egg mass quantity lost per day for 1 Torr pressure difference across the eggshell, according to the method described by Ar et al (1974). The water vapor pressure inside the egg is saturated and in the desiccators, it is zero. Thus, by dividing the daily mass loss by the saturation vapor pressure of 23.922 torr

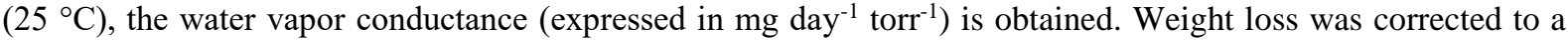
barometric pressure of 1 atmosphere as described by Ar et al (1974).

Water vapor conductance of eggshell was calculated by using the following equations:

$$
G_{\mathrm{H}_{2} \mathrm{O}}=\frac{M_{\mathrm{H}_{2} \mathrm{O}}}{\Delta P_{\mathrm{H}_{2} \mathrm{O}}}
$$

Where; $G_{\mathrm{H}_{2} \mathrm{O}}=$ water vapor conductance $\left(\mathrm{mg} *\right.$ day $\left.^{-1} \operatorname{torr}^{-1}\right) ; M_{\mathrm{H}_{2} \mathrm{O}}=$ the rate of weight loss $\left(\mathrm{mg} * \mathrm{day}^{-1}\right)$; $\Delta P_{\mathrm{H}_{2} \mathrm{O}}=$ water vapor pressure difference.

\subsection{Data analysis}

Data were analyzed using descriptive Statistics, t-Test: two-sample as summing equal variances using SAS (2008). Pearson correlation was used to determine the correlation of different parameters of eggshell characteristics. Mortality data was analyzed using chi-square test.

\section{Results and Discussion}

In this study, two early embryonic deaths were determined in 28 wk flock, whereas one early embryonic death and two late embryonic deaths was found in 40 wk-old flock. Two unfertile eggs were determined in both of the flocks. By considering these values percentages of fertility in 28 wk-old flock and 40 wk-old flock was found to be similar (95\%). The mortality did not differ between the two groups. Hatchability of fertile eggs was numerically found higher in 28 wk-old flock $(94.74 \%)$ than in 40 wk-old flock $(92.10 \%)$ although it was not significantly different between the groups (chi-square=0.188. P>0.665). Smilarly Iqbal et al (2016) found reduced hatchability and increased embryonic mortality with the advanced age of the breeder.

Water vapor conductance of 28 wk-old flock and 40 wk-old flocks is presented in Table 1 . In the present study, eggshell water vapor conductance was affected by flock age, conductance $(\mathrm{G})$ value was $11.00 \pm 1.01 \mathrm{mg}$ $\mathrm{H}_{2} \mathrm{O}$ day $^{-1}$ torr $^{-1}$ and $11.99 \pm 1.28 \mathrm{mg} \mathrm{H}_{2} \mathrm{O}$ day $^{-1}$ torr $^{-1}$ in 28 and 40 wk-old flock, respectively $(\mathrm{P}<0.05)$. In accordance with Morita et al (2009) who found that eggs obtained from older breeders possess higher water vapor conductance. Christensen et al (2005) also found that young flock hens produce thicker eggshells and light chicks due to a less exchange of gases and lower eggshell conductance than older flocks. French \& Tullet (1991) reported that $\mathrm{GH}_{2} \mathrm{O}$ shows an increment in the first half of the laying cycle, then becomes moderate and constant, and finally increased again at the end of the laying cycle. O'Dea et al (2004) found that eggs from 37 wk-old flock had higher water vapor conductance compared with eggs from 35-43 wk-old flocks. Meir \& Ar ( 2008) also reported with the increase of flock age, water vapor conductance also shows an increment in layer hens. Meanwhile, Araujo et al (2017) had calculated the conductance of eggshells by using shell fragments from hatched eggs and results showed that water vapor conductance increased with the increasing flock age. In contrast, Nangsuay et al (2016) reported that eggs obtained from young and older flocks did not differ in eggshell conductance. Hocking et al (2009) found that increased conductance facilitates oxygen uptake of the embryo 
during late period of incubation. Bamelis et al (2008) showed that increasing conductance rate could be the reason for high embryonic mortality. In the present study, late embryonic mortality was observed in only $40 \mathrm{wk}-$ old flock at the same time eggshell conductance was also found statistically higher this flock age.

Table 1- Water vapor conductance in 28 and 40 wk-old broiler breeders $\left(25^{\circ} \mathrm{C}\right.$ temperature and zero humidity)

\begin{tabular}{|c|c|c|c|c|c|c|c|}
\hline Group & $n$ & $\begin{array}{c}\text { Fresh egg wt } \\
(g)\end{array}$ & $\begin{array}{c}24 h r \text { egg wt } \\
(g)\end{array}$ & $\begin{array}{c}48 \text { hr egg wt } \\
(g)\end{array}$ & $\begin{array}{c}72 \text { hr egg wt } \\
(g)\end{array}$ & $\begin{array}{c}92 \mathrm{hr} \text { egg wt } \\
(\mathrm{g})\end{array}$ & $\begin{array}{c}W V C \\
m g * d a y^{-1} \text { torr }^{-1}\end{array}$ \\
\hline 28 week & 25 & $58.06 \pm 1.71$ & $57.90 \pm 1.73$ & $57.75 \pm 1.73$ & $57.60 \pm 1.74$ & $57.43 \pm 1.74$ & $11.00 \pm 1.01$ \\
\hline 40 week & 25 & $58.78 \pm 1.77$ & $58.60 \pm 1.77$ & $58.44 \pm 1.78$ & $58.29 \pm 1.78$ & $58.11 \pm 1.79$ & $11.99 \pm 1.28$ \\
\hline \multicolumn{2}{|c|}{ Significance } & 0.150 & 0.166 & 0.169 & 0.173 & 0.177 & 0.004 \\
\hline
\end{tabular}

WVC, water vapor conductance

Eggshell characteristics of hatched eggs in 28 wk-old flock and 40 wk-old flocks are presented in Table 2. The mean shell thickness and pore density were affected by flock age $(\mathrm{P}<0.01)$. The mean shell thickness and pore density were found higher in 28 wk-old flock than in 40 wk-old flock. Additionally, both of two regions (broad and equator) of shell thickness and pore density were found higher in 28 wk-old flock $(\mathrm{P}<0.01)$. Surface area was numerically higher in 40 wk-old flock $\left(71.40 \mathrm{~cm}^{2} \pm 1.83\right)$ whereas volume was numerically higher in 28 wk flock $\left(25.32 \mathrm{~cm}^{3} \pm 1.75\right)$. Both of them are important geometrical calculations for the poultry industry and can be used to predict chick weight, egg hatchability, shell quality characteristics, and egg interior parameters (Zhou et al 2009). The association was related to increased egg size and a decreased eggshell surface area to egg volume ratio (Peebles \& Brake 1987).

Table 2- Eggshell characteristics of hatched eggs in 28 and 40 wk-old broiler breeders

\begin{tabular}{|c|c|c|c|}
\hline Parameters & 28 week $^{l}$ & 40 week $^{2}$ & Significance \\
\hline Initial egg weight, $\mathrm{g}$ & $57.28 \pm 1.75$ & $57.97 \pm 1.64$ & 0.091 \\
\hline Egg weight loss, \% & $9.49 \pm 1.31$ & $9.76 \pm 1.55$ & 0.432 \\
\hline Thickness, mm & $0.36 \pm 0.02$ & $0.34 \pm 0.02$ & 0.000 \\
\hline Broad end, mm & $0.37 \pm 0.02$ & $0.36 \pm 0.02$ & 0.044 \\
\hline Equator, mm & $0.37 \pm 0.02$ & $0.32 \pm 0.03$ & 0.000 \\
\hline Narrow end, mm & $0.33 \pm 0.02$ & $0.33 \pm 0.02$ & 0.383 \\
\hline Pore density, pore $/ \mathrm{cm}^{2}$ & $43.2 \pm 15.11$ & $30.3 \pm 11.51$ & 0.000 \\
\hline Broad end, pore $/ \mathrm{cm}^{2}$ & $52.6 \pm 21.90$ & $36.7 \pm 20.00$ & 0.002 \\
\hline Equator, pore $/ \mathrm{cm}^{2}$ & $46.3 \pm 19.62$ & $29.8 \pm 12.01$ & 0.000 \\
\hline Narrow end, pore $/ \mathrm{cm}^{2}$ & $29.1 \pm 12.51$ & $24.5 \pm 12.90$ & 0.129 \\
\hline Surface area, $\mathrm{cm}^{2}$ & $69.99 \pm 1.20$ & $71.11 \pm 1.45$ & 0.001 \\
\hline Volume, $\mathrm{cm}^{3}$ & $25.32 \pm 1.75$ & $24.12 \pm 1.58$ & 0.003 \\
\hline
\end{tabular}

${ }^{1}, \mathrm{n}=36$ eggs; ${ }^{2}, \mathrm{n}=35$ eggs

Gualhanone et al (2012) found that with the increase of age in different flocks shell thickness also tends to decreases. Roland et al (1988) reported that with the increment of hen's age, shell thickness decreases because total shell deposition after the first three months of laying period remains fairly constant while eggs continue to increase in size. It causes a thinner shell and a deterioration of shell quality (Hamilton et al 1979). In contrast to this result, in another study, it was reported that shell thickness was not influenced by flock age (Kontecka et al 2012).

Pore size has an important role for the shell conductance and the determination of the respiratory rate of an embryo. It is estimated that there are between 100 and 300 pores per $\mathrm{cm}^{2}$ of the shell surface (Gilbert 1971). It can be inferred that eggshell conductance does not depend only on shell thickness. The main factor may be the number of pores, present in the eggshell (Araujo et al 2017). In this study flock age significantly affected the 
number of pores except for the narrow region $(\mathrm{P}<0.01)$. The mean of pore density of eggshells was higher in 28 wk-old flock age than in 40 wk-old flock (Table 2). In contrast, Shanawany et al (1984) and Araujo et al (2017) reported that older breeders produce eggs with higher total pore number than young flock ages. These results are in contrast to our findings because only large pores were counted. The mean pore of two regions (broad and equator) were $52.6 \pm 21.9,46.3 \pm 19.6$ of eggshell were higher in 28 wk-old flock while as in 40 wk-old flock it was found 36.7 $\pm 20.0,29.8 \pm 12.0$ (Table 2). The results were in accordance with Ancel \& Girad (1992) who reported that the greater number of the pore in the broad and equator region of eggshell. Meir \& Ar (2008) found that porosity is main factor for the determinant of water loss from the egg. Similarly, Deeming et al (2002) reported that egg water loss depends on eggshell porosity, pore number, length and shape of the pore. In this study egg weight loss was not found to be significant in two flock ages. In the present study, it may be concluded that there was not any difference in egg weight loss in between two flock ages, due to lower pore density in the eggshell of 40 wk flock. In contrast, this result Reis et al (1997) showed that eggs from older breeders had higher weight loss than younger breeders. Normally accepted average egg weight loss is $12 \%$ while as, Carey et al (1986) reported that individual embryos could tolerate a wide range of condition and they can be successfully hatched. Similarly, in our study despite lower than $12 \%$ average egg weight, hatchability was not much affected.

Correlation of eggshell characteristics in 28 and 40 wk-old flocks are shown in Table 3 and 4 . A nonsignificant correlation was found between mean eggshell thickness and mean pore density along with the three regions in 28 wk-old flock age and 40 wk-old flock age. While a positive correlation was found between mean thickness and three regions of eggshell in both flocks $(\mathrm{P}<0.01)$. Araujo et al $(2017)$ found a positive correlation only between eggshell porosity and three regions of eggshell in $29,35,59$ wk flock ages. Peeble \& Brake (1987) reported relative porosity of eggs laid during early production may be higher due to their larger surface area to volume ratio. In our study, there are some significant correlations between volume and mean thickness $(\mathrm{r}=$ 0.935) and the thickness in three regions of eggshell in 40 wk-old flock. A significant positive correlation was found in between initial weight and volume in 28 wk-old flock. $(\mathrm{r}=0.346, \mathrm{P}<0.05)$. There was a positive correlation between mean thickness and volume in 28 wk-old flock age $(r=0.912)$ and also in 40 wk-old flock age $(r=0.935 ; \mathrm{P}<0.01)$. A non-significant correlation was found between initial egg weight and eggshell thickness and pore density additionally between mass loss and eggshell thickness and pore density. However, Gualhanone et al (2012) reported that eggshell thickness, egg weight may have a correlation with breeder age.

Table 3- Correlation of eggshell characteristics in 28 wk-old broiler breeder

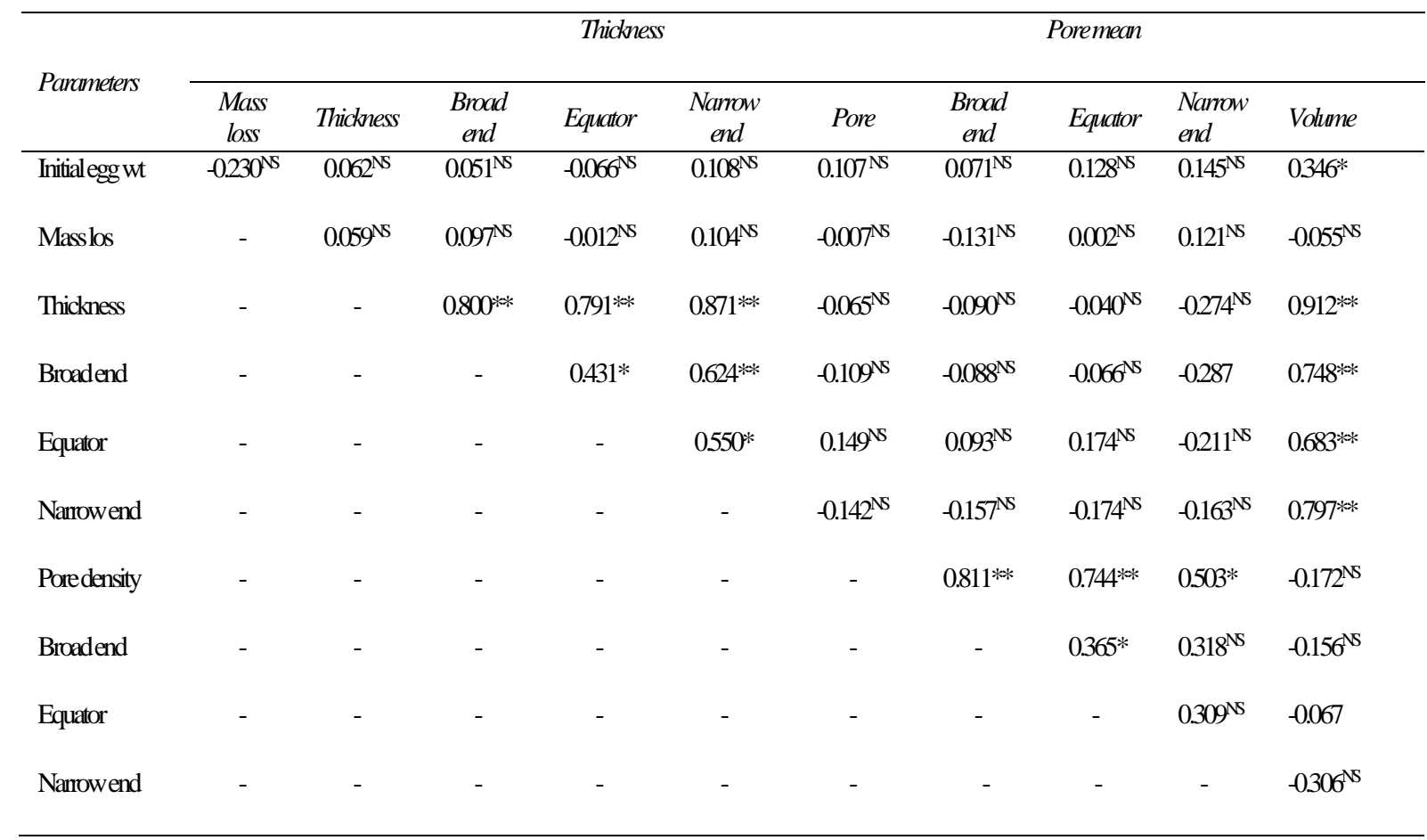

**: $P<0.01 ; *: P<0.05$; NS: Not Significant 
Table 4- Correlation of eggshell characteristics in 40 wk-old broiler breeder

\begin{tabular}{|c|c|c|c|c|c|c|c|c|c|c|}
\hline \multirow{2}{*}{ Parameters } & \multicolumn{5}{|c|}{ Thickness } & \multicolumn{5}{|c|}{ Pore Density } \\
\hline & $\begin{array}{l}\text { Mass } \\
\text { loss }\end{array}$ & Thickness & $\begin{array}{l}\text { Broad } \\
\text { end }\end{array}$ & Equator & $\begin{array}{l}\text { Narrow } \\
\text { end }\end{array}$ & $\begin{array}{l}\text { Pore } \\
\text { density }\end{array}$ & $\begin{array}{l}\text { Broad } \\
\text { end }\end{array}$ & Equator & $\begin{array}{l}\text { Narrow } \\
\text { end }\end{array}$ & Volume \\
\hline Initial egg wt & $0.008^{\mathrm{NS}}$ & $-0.223^{\mathrm{NS}}$ & $-0.125^{\mathrm{NS}}$ & $-0.108^{\mathrm{NS}}$ & $-0.244^{\mathrm{NS}}$ & $-0.113^{\mathrm{NS}}$ & $-0.084^{\mathrm{NS}}$ & $-0.093^{\mathrm{NS}}$ & $-0.088^{\mathrm{NS}}$ & $0.014^{\mathrm{NS}}$ \\
\hline Mass loss & - & $-0.225^{\mathrm{NS}}$ & $-0.348^{*}$ & $-0.082^{\mathrm{NS}}$ & $-0.030^{\mathrm{NS}}$ & $0.093^{\mathrm{NS}}$ & $0.123^{\mathrm{NS}}$ & $-0.053^{\mathrm{NS}}$ & $0.105^{\mathrm{NS}}$ & $-0.301^{\mathrm{NS}}$ \\
\hline Thickness & - & - & $0.729 * *$ & $0.709 * *$ & $0.595 * *$ & $0.091^{\mathrm{NS}}$ & $0.075^{\mathrm{NS}}$ & $0.156^{\mathrm{NS}}$ & $-0.018^{\mathrm{NS}}$ & $0.935 * *$ \\
\hline Broad end & - & - & - & $0.292^{\mathrm{NS}}$ & $0.212^{\mathrm{NS}}$ & $-0.039^{\mathrm{NS}}$ & $-0.031^{\mathrm{NS}}$ & $-0.054^{\mathrm{NS}}$ & $-0.007^{\mathrm{NS}}$ & $0.720 * *$ \\
\hline Equator & - & - & - & - & $-0.071^{\mathrm{NS}}$ & $0.122^{\mathrm{NS}}$ & $0.179^{\mathrm{NS}}$ & $0.168^{\mathrm{NS}}$ & $-0.102^{\mathrm{NS}}$ & $0.689 * *$ \\
\hline Narrow end & - & - & - & - & - & $0.111^{\mathrm{NS}}$ & $-0.004^{\mathrm{NS}}$ & $0.208^{\mathrm{NS}}$ & $0.107^{\mathrm{NS}}$ & $0.483^{*}$ \\
\hline Pore density & - & - & - & - & - & - & $0.805 * *$ & $0.695^{* *}$ & $0.786^{* *}$ & $0.086^{\mathrm{NS}}$ \\
\hline Broad end & - & - & - & - & - & - & - & $0.244^{\mathrm{NS}}$ & $0.379 *$ & $0.101^{\mathrm{NS}}$ \\
\hline Equator & - & - & - & - & - & - & - & - & $0.556^{*}$ & $0.124^{\mathrm{NS}}$ \\
\hline Narrow end & - & - & - & - & - & - & - & - & - & $-0.042^{\mathrm{NS}}$ \\
\hline
\end{tabular}

**, $\mathrm{P}<0.01 ; *, \mathrm{P}<0.05 ; \mathrm{NS}$, Not Significant

\section{Conclusions}

Eggshell quality such as conductance, thickness, and pore density are an important characteristic that affects the embryonic gas exchange and development of the embryo. The relationship between these parameters such as, eggshell conductance and flock age should be taken in consideration for debating their impacts on hatching output. Use of desiccators for determining the eggshell conductance before incubation most importantly for different age groups is a beneficial tool for selecting the appropriate scenario of incubation including temperature and relative humidity to achieve the better results of hatching and growth of hatched chicks. It is suggested that the broiler breeder should determine the functional properties of the particular eggs that they are using so that hatchability and hatching quality can be improved by matching incubator conditions to these eggs.

\section{Acknowledgments}

We would like to thank commercial breeder farm HasTavuk for their support and contribution.

\section{References}

Ancel A \& Girard H (1992). Eggshell of the domestic guinea fowl. British Poultry Science 33(5): 993-1001

Ar A, Paganelli C V, Reeves R B, Greene D G \& Rahn H (1974). The avian egg: Water vapor conductance, shell thickness and functional pore area. Condor 76: 153-158

Araujo I C S, Leandro N S M, Meaquita M A, Cafe M A, Mello H H C \& Gonzales E (2017). Water vapor conductance: a technique using eggshell fragments and relations with other parameters of eggshell. Revista Brasileira de Zootecnia 46(12): 896-902

Aviagen (2010). Ross: Ross Breeder Parent Stock Management Guide. Retrieved in June, 15, 2013 from http://en.aviagen.com/assets/Tech_Center/BB_Resources_Tools/Pocket_Guides/Ross-PS-Pocket-Guide2013EN. pdf

Bamelis F R, De Ketelaere B, Mertens K, Kemps Bn J, Decuypere E M \& De Baerdemaeker J G (2008). Measuring the conductance of eggshells using the acoustic resonance technique and optical transmission spectra. Computers and Electronics in Agriculture 60: 35-40

Board R G \& Halls N A (1973). The cuticle: a barrier to liquid and particle penetration of the shell of the hen's egg. British Poultry Science 14(1): 69-79 
Carey C (1986). Tolerance in variation in eggshell conductance, water loss, and water content by Red-winged Blackbird embryos. Physiological Zoology 59(1): 109-122

Christensen V L, Wineland M J, Ort D T \& Mann K M (2005). Eggshell conductance and incubator ventilation as factors in embryo survival and poultry quality. International Journal of Poultry Science 4(11): 818-826

Deeming D C (2002). Avian Incubation: Behaviour, Environment, and Evolution. Oxford University Press, Oxford, 421

French N A \& Tullett S G (1991). Variation in the eggs of poultry species. In Avian Incubation (S. G. Tullett, ed.). Butterworth and Heinemann, London, 59-77

Gilbert A B (1971). The egg: Its physical and chemical aspects. In: Physiology and Biochemistry of the Domestic Fowl. vol 3, eds Bell, D. J. and Freeman. B.M. Academic, New York, pp. 1379-1399

Gualhanone A, Furlan R L, Fernandez-Alarcon M F \& Macari M (2012). Effect of breeder age on eggshell thickness, surface temperature, hatchability and chick weigh. Brazilian Journal of Poultry Science 14(1): 9-14

Hamidu J A, Fasenko G M, Feddes J J R, O’Dea E E, Ouellette C A, Wineland M J \& Christensen V L (2007). The Effect of Broiler Breeder Genetic Strain and Parent Flock Age on Eggshell Conductance and Embryonic Metabolism. Poultry Science 86(11): 2420-2432

Hamilton R M G, Hollands K G, Voisey P W \& Grunder A A (1979). Relationship between eggshell quality and shell breakage and factors that affect shell breakage in the field-a review. World's Poultry Science Journal 35: 177-190

Hocking P.M (2009). Biology of Breeding Poultry, Poultry Science Symposium Series, vol. 29, CABI, Wallingford, UK. pp. 208

Ipek A \& Sahan U (2001). Effect of specific gravity and flock age on hatching traits in broiler breeders. Turkish Journal of Veterinary and Animal Science 25(6): 817-821

Kontecka H, Nowaczewski S \& Sierszuła M M (2012). Analysis of changes in egg quality of broiler breeders during the first reproduction period. Annals of Animal Science 12(4): 609-620

Meir M \& Ar A (2008). Changes in eggshell conductance, water loss and hatchability of layer hens with flock age and moulting. British Poultry Science 49(6): 677-684

Morita V S, Boleli I C \& Cargnelutti Filho A (2009). Hematological values and body, heart and liver weights in male and female broiler embryos taken from eggs of young and old breeders. Brazilian Journal of Poultry Science 11(1): 19-27

Nangsuay A, Meijerhof R, van den Anker I, Heetkamp M J W, De Souza Morita V, Kemp B \& van den Brand H (2016). Effects of breeder age, broiler strain, and eggshell temperature on development and physiological status of embryos and hatchlings. Poultry Science 95(7): 1666-1679

NRC (National Research Council) (1994). Nutrient Requirements of Poultry. Ninth Revised Edition. National Academy Press, Washington, DC

O’Dea E E, Fasenko G M, Feddes J J R, Robinson F E, Segura J C, Ouellette C A \& van Middelkoop J H (2004). Investigating the eggshell conductance and embryonic metabolism of modern and unselected domestic avian genetic strains at two flock ages. Poultry Science 83: 2059-2070

Paganelli C V, Olszowka A \& Ar A (1974). The avian egg: surface area, volume, and density. The Condor 76(3): 319-325

Peeble E D \& Cristropher D M (2013). A practical manual for understanding the shell structure of broiler hatching eggs and measurement of their quality. Mississippi agricultural \& forestry experiment station Bulletin pp. 1139

Peebles E D \& Brake J (1987). Eggshell quality and hatchability in broiler breeder eggs. Poultry Science 66(4): 596-604

Peebles E D, Gardner C W, Brake J, Benton C E, Bruzual J J \& Gerard P D (2000). Albumen height and yolk and embryo compositions in broiler hatching eggs during incubation. Poultry Science 79(10): 1373-1377

Reis L H, Gama L T \& Soares M C (1997). Effects of short storage conditions and broiler breeder age on hatchability, hatching time, and chick weights. Poultry Science 76(11): 1459-1466 
Roland D A (1988). Eggshell breakage: Incidence and economic impact. Poultry Science 67(12): 1801-1803

Roque L \& Soares M C (1994). Effects of eggshell quality and broiler breeder age on hatchability. Poultry Science 73(12): $1838-1845$

SAS (2008). SAS User's Guide: Statistics, $9^{\text {th }}$ edition. SAS Institute, Inc., Cary, North Carolina

Shanawany M M (1984). The interrelationship between egg weight parental age and embryonic size. British Poultry Science 25(4): 449-455

Tullett S G (1981). Theoretical and practical aspects of eggshell porosity. Turkeys 29: 24-28

Tullett S G (1990). Science and the art of incubation. Poultry Science 69(1): 1-15

Vieira S L \& Moran Jr E T (1999). Effects of egg of origin and chick post-hatch nutrition on broiler live performance and meat yields. World's Poultry Science Journal 55(2): 125-142

Visschedijk A H J (1983). The importance of convection in the determination of the water vapor conductance of avian egg shell. British Poultry Science 24(1): 47-56

Visschedijk A H J (1991). Gordon Memorial Lecture: Physics and physiology of incubation. British Poultry Science 32(1): $3-20$

Zhou P, Zheng W, Zhao C, Shen C \& Sun G (2009). Egg volume and surface area calculations based on machine vision. In IFIP International Federation for Information Processing, Volume 295, Computer and Computing Technologies in Agriculture II, Volume 3, eds. D. Li, Z. Chunjiang, Boston: Springer, pp. 1647-1653 